\title{
Interactive comment on "Future streamflow regime changes in the United States: assessment using functional classification" by Manuela I. Brunner et al.
}

\section{Manuela I. Brunner et al.}

manuela.i.brunner@gmail.com

Received and published: 26 May 2020

Please find our responses to the reviewer's comments in the PDF attached.

Please also note the supplement to this comment:

https://www.hydrol-earth-syst-sci-discuss.net/hess-2020-54/hess-2020-54-AC4-

supplement.pdf 